Etnográfica

Revista do Centro em Rede de Investigação em

Antropologia

vol. $24(2) \mid 2020$

Vol. $24(2)$

\title{
Etnografiando (in)movilidades: la tecnología móvil como dimensión del habitar isleño
}

The ethnography of (im)mobilities: mobile technology as a dimension of islanders' life

Alejandra Lazo Corvalán, Diego Carvajal Hicks y Hernán Riquelme Brevis

\section{(2) OpenEdition}

Journals

Edición electrónica

URL: https://journals.openedition.org/etnografica/7887

DOI: $10.4000 /$ etnografica.7887

ISSN: 2182-2891

\section{Editor}

Centro em Rede de Investigação em Antropologia

Edición impresa

Fecha de publicación: 1 junio 2020

Paginación: 269-288

ISSN: 0873-6561

\section{Referencia electrónica}

Alejandra Lazo Corvalán, Diego Carvajal Hicks y Hernán Riquelme Brevis, «Etnografiando

(in)movilidades: la tecnología móvil como dimensión del habitar isleño», Etnográfica [En línea], vol. 24

(2) | 2020, Publicado el 31 julio 2020, consultado el 21 enero 2022. URL: http://

journals.openedition.org/etnografica/7887 ; DOI: https://doi.org/10.4000/etnografica.7887

\section{(c) (1) (8)}

Etnográfica is licensed under a Creative Commons Attribution-NonCommercial 4.0 International License. 


\section{Etnografiando (in)movilidades: la tecnología móvil como dimensión del habitar isleño}

\section{Alejandra Lazo Corvalán, Diego Carvajal Hicks y Hernán Riquelme Brevis}

A partir de una etnografía del muelle de Achao y de la experiencia de dos jóvenes isleños, se demuestra como la movilidad cotidiana se ha modificado con la llegada de tecnologías y objetos a las islas. Se postula que la llegada y uso de estos objetos - en particular del smartphone - sirven para el desplazamiento espaciotemporal de territorios antes no explorados debido a la exclusión espacial y a una modernidad tecnológica rezagada. Demostramos que estos usos constituyen una práctica y experiencia que, desde la promesa neoliberal "de lo móvil", mantiene y gobierna una inmovilidad del malestar. Finalmente, se argumenta que la movilidad en Quinchao (Chiloé) no sólo puede pensarse desde el movimiento efectivo o conectivo en lancha, sino desde la inmovilidad y la espera, donde cobra sentido el uso cotidiano del celular como amortiguador de las tensiones entre movilidad e inmovilidad presentes en las islas.

PALABRAS CLAVE: inmovilidades, espera, smartphones, neoliberalismo, islas de Chiloé.

The ethnography of (im)mobilities: mobile technology as a dimension of islanders' life - Based on an ethnography of the pier of Achao and the experience of two young islanders, it is demonstrated how the daily mobility has been modified with the arrival of new technologies and objects on the islands. On the one hand, it is postulated that the arrival and use of these objects - especially the smartphone - serves for the space-time displacement of previously unexplored territories, due to spatial exclusion and a lagging technological modernity. On the other hand, it is a practice and experience that draws on the neoliberal promise "of the mobile" to maintain and govern an immobility of discomfort. It is argued that mobility in Quinchao (Chiloé) can be thought beyond the effective or connective movement in the boat to include the immobility and waiting, where the daily use of the cellphone makes great sense as a buffer against the tensions between mobility and immobility present in the islands.

KEYWORDS: immobility, waiting, smartphone, neoliberalism, islands of Chiloé.

LAZO CORVALÁN, Alejandra (alejandra.lazo@ulagos.cl) - CEDER, Universidad de Los Lagos, Chile.

CARVAJAL HICKS, Diego (diegocarvajalhicks@gmail.com) - Universidad Católica de Chile, Chile.

RIQUELME BREVIS, Hernán (h.riquelmebrevis@gmail.com) - Universidad Autónoma de Chile; UIIP-UNAP, Chile. 


\section{INTRODUCCIÓN: LA ESPERA Y EL SMARTPHONE COMO DIMENSIONES} DEL HABITAR ISLEÑO

Chiloé es un archipiélago ubicado en el sur austral de Chile, en la Décima Región de los Lagos. ${ }^{1}$ Su isla principal es la llamada Isla Grande de Chiloé, separada del continente al norte por el canal de Chacao y compuesta por el Golfo de Ancud y el de Corcovado. Es la segunda isla más grande en superficie del país, reuniendo a cerca de 155.000 habitantes, dos ciudades principales, Castro al este y Ancud al norte, y está agregada a varias islas pequeñas. Una de las principales características geográficas y culturales de este archipiélago es "la espera", variable del habitar insular. Esta dimensión nos resulta clave para entender un habitar marcado por los ritmos estacionarios y el movimiento del mar. La movilidad aquí es una práctica compleja y "turbulenta" (Cresswell 2010), donde la cotidianeidad se establece en clave "elusiva” (Vannini 201 la) en relación con el abordaje o el tiempo de espera que resta para la próxima salida.

En efecto, la espera siempre ha estado relacionada con la movilidad efectiva o proyectada desde la inmovilidad (Bissell 2007; Campos y Aguilar 2015), lo que se acentúa cuando se vive en islas alejadas de los centros urbanos y del continente. La espera será una experiencia de movilidad para sortear la "fricción" (Vannini 20l lb) que implica vivir aislado y excluido espacialmente (Grenier 1984). Efectivamente, para un joven isleño, vivir más allá del pueblo de Achao implica vivir sin mucha interacción local y vecinal, en islas pequeñas y despobladas. Significa, en algunos casos, vivir en una espera cotidiana y activa, imaginando otra realidad.

Si para el caso de un chileno continental existe aquel imaginario histórico de vivir "al fin del mundo" (Salazar 2013), en el caso de estas islas, este imaginario migratorio (Appadurai 2001) se intensifica. Se trata de una inmovilidad que no es aquietada, sino fuertemente relativizada desde las tecnologías, las imágenes y las (nuevas) formas de territorializar en un contexto global, lo que hace que las motivaciones y capacidades para cruzar fronteras sean múltiples y tengan relación con las redes sociales y discursos disponibles para imaginar y conocer otros lugares (Salazar 2011). Para el caso de Chiloé, será el emplazamiento de la industria acuícola desde la década de 1970 (Yáñez 2011) un acontecimiento que promueve e intensifica el desarrollo de flujos migratorios juveniles en la región (Gobantes 2011), como también la imagen de progreso y de emprendimiento individual asociada a "lo diferente en cuanto isla".

Actualmente, este imaginario se relaciona con las movilidades, con los límites de cada isla y con la experiencia misma de la espera por salir, que se contiene y se sortea por medio de la experiencia de los celulares y su materialidad

I Los autores agradecen a Conicyt y Fondecyt por el financiamiento del proyecto de postdoctorado 3140115. 
tecnológica. Pareciera ser que la movilidad actual está influida por las nuevas tecnologías de comunicación, artefactos e infraestructuras (Tironi Rodó 2009) y en cómo estas se relacionan con contextos capitalistas y modernos donde se modifica la experiencia de aceleración, circulación y el ritmo de vida (Sheller y Urry 2006). Hay una relación "socio-técnica" (Latour 2005) que opera como lugar múltiple, ensamblado y afectivo (Bissell 2007 Massumi 1995), una experimentación relacional entre objetos y humanos (Latour 2005) que hace de la espera por salir una forma constante de actualización.

Los dispositivos celulares, siguiendo a Lemos, se convierten en una forma de desplazamiento donde la "dinámica se tensa entre lo cercano y lo distante [...] hay relaciones sociales, hay movimiento, reposo, aislamiento y agregación, compulsión social y necesidad de aislamiento" (Lemos 2010: 1). Todo lo anterior acontece desde una "telepresencia" (Pirela 2001: 103) digital y física que modificaría la experiencia de moverse o no moverse en el territorio. Desde este objeto tecnológico, la movilidad y el transporte parece experimentarse a alta velocidad (Castells 1996) y de forma "fluida" (Bauman 2003) por el espacio.

La experiencia del celular aseguraría que la acción de aferrarse al lugar ya no sea tan importante (Bauman 1999), de ahí que la movilidad se establezca de forma instantánea y los límites espaciales se pierdan (Bauman 1999), en tanto se conciben como dependencia o paralización (Bauman 2003). Se trata de una frontera abierta, propia del mercado (Appadurai 2001) y de los flujos de información dominantes (Castells 1994) que, en el caso isleño, desde la televisión hasta el celular, aparecen en clave "mediática y política" (Arancibia 2002) como integración, acceso y democracia.

Experiencias como la espera en territorios tan alejados como el muelle de Achao serán centrales para entender cómo la gente vive y experimenta esa "inmovilidad" archipelágica. Es en este lugar, límite entre la vida isleña y la urbanización de la experiencia móvil, donde el momento conectivo de embarque y desembarque se torna crucial (Lazo y Ther 2014). En el muelle hay transacciones de dinero y comunicaciones inmediatas para agenciar una llegada, una conexión, para "ubicarse" o actualizarse.

Pero no sólo se trata de esperar y coordinar. En los viajes también se observa el uso que tienen estos aparatos. Los jóvenes llevan siempre en sus manos un celular desde el cual configuran otras formas de percibir y acelerar el espacio-tiempo que falta entre un lugar y otro. En efecto, el tiempo del viaje en los jóvenes se apresura en la constante actualización del dispositivo.

En la lancha, la precariedad del contexto parece no ser importante, ya que la mayoría luce objetos tecnológicos que contrastan con sus sencillas realidades económicas. Lo que da cuenta de cómo Chile, a pesar de que ha presentado importantes índices de crecimiento económico, exhibe importantes asimetrías respecto a salarios, pobreza y privatización de los servicios básicos (Ffrench-Davis 2001; Garretón 2012). 
Bajo este contexto de precariedad, insularidad, espera y neoliberalismo es que el presente artículo se focaliza desde una mirada antropológica en analizar las tecnologías móviles, específicamente el uso del celular en jóvenes, enfatizando su cruce con la inmovilidad, sus variantes culturales y formas de ser experimentada. Específicamente, observamos en las islas investigadas cómo hay experiencias disímiles para los jóvenes. En términos específicos y en relación al trabajo de campo, para uno de los jóvenes que habita en la isla de Chaulinec, hay estabilidad económica-espacial y la tecnología móvil sirve para conectarse y para el trabajo flexible. Y al frente, en la precaria y pequeña isla de Alao, emergen dos jóvenes hermanos que usan la tecnología de forma específica, para sobrellevar el malestar de la inmovilidad y su deseo de migración. Estas dos experiencias permiten acercarnos a cómo el uso de esta tecnología diagrama las relaciones de movilidad e inmovilidad que existen hoy en el archipiélago de Chiloé.

Hemos dividido la discusión de la siguiente manera: en una primera parte hacemos un pequeño recorrido por cómo la modernización ha ido transformando el territorio archipelágico y sus relaciones; observaremos en seguida el presente de una inmovilidad que transcurre desde una multiplicidad de objetos y donde las tecnologías son fundamentales para la experiencia de viaje; finalmente, presentamos dos etnografías de jóvenes isleños que muestran la relación con el smarthphone, la inmovilidad y movilidad insular.

\section{EL CONTEXTO ARCHIPELÁGICO Y LA ETNOGRAFÍA MÓVIL}

Para este artículo se consideraron solo dos de las nueve islas estudiadas, Alao y Chaulinec. ${ }^{2}$ Estas islas se encuentran separadas por el Canal de Chaulinec, en Quinchao, y mantienen comunicaciones permanentes vía lancha. Cada isla tiene sus propios medios de transporte, que son las lanchas de recorrido. En Chaulinec está la lancha llamada Contanza Andrea, que sale hacia el pueblo de Achao de ida y vuelta todos los días excepto los sábados. En Alao está la lancha Pez Mar, que también sale todos los días, a excepción del día jueves. El muelle, la iglesia, una pequeña posta, la junta de vecinos, un almacén, la escuela rural, son algunos de los servicios con los que cuentan la mayoría de las islas. No se ve mucha gente en sus caminos y espacios cotidianos. El tiempo transcurre de forma lenta y lo único que lo altera e intensifica parcialmente es la llegada/

2 La isla de Alao tiene $8,8 \mathrm{~km}^{2}$ de superficie y está dividida en varios sectores: Apao, Cumblelo o Cumelelo, Duo, Huechún, La Capilla, La Vega, Lahual y Miraflores. Según el Censo del 2002, había 462 personas repartidas en 121 viviendas, todas rurales (INE 2002). Chaulinec tiene 27,3 $\mathrm{km}^{2} \mathrm{de}$ superficie y está dividida en los sectores de Capilla Antigua, La Villa, Huelmo, Llahuach y Quentol. Según el Censo del 2002, la población era enteramente rural y alcanzaba las 653 personas repartidas en 175 viviendas (INE 2002). 
salida de las lanchas. En ambas islas, la extracción y venta de luga, pelín y pelillo se instala como una de las principales actividades económicas para conseguir dinero inmediato (Morales 2011).

En relación con lo anterior, y pensando en la metodología más adecuada para estudiar este tipo de contextos, nos pareció conveniente recurrir a la

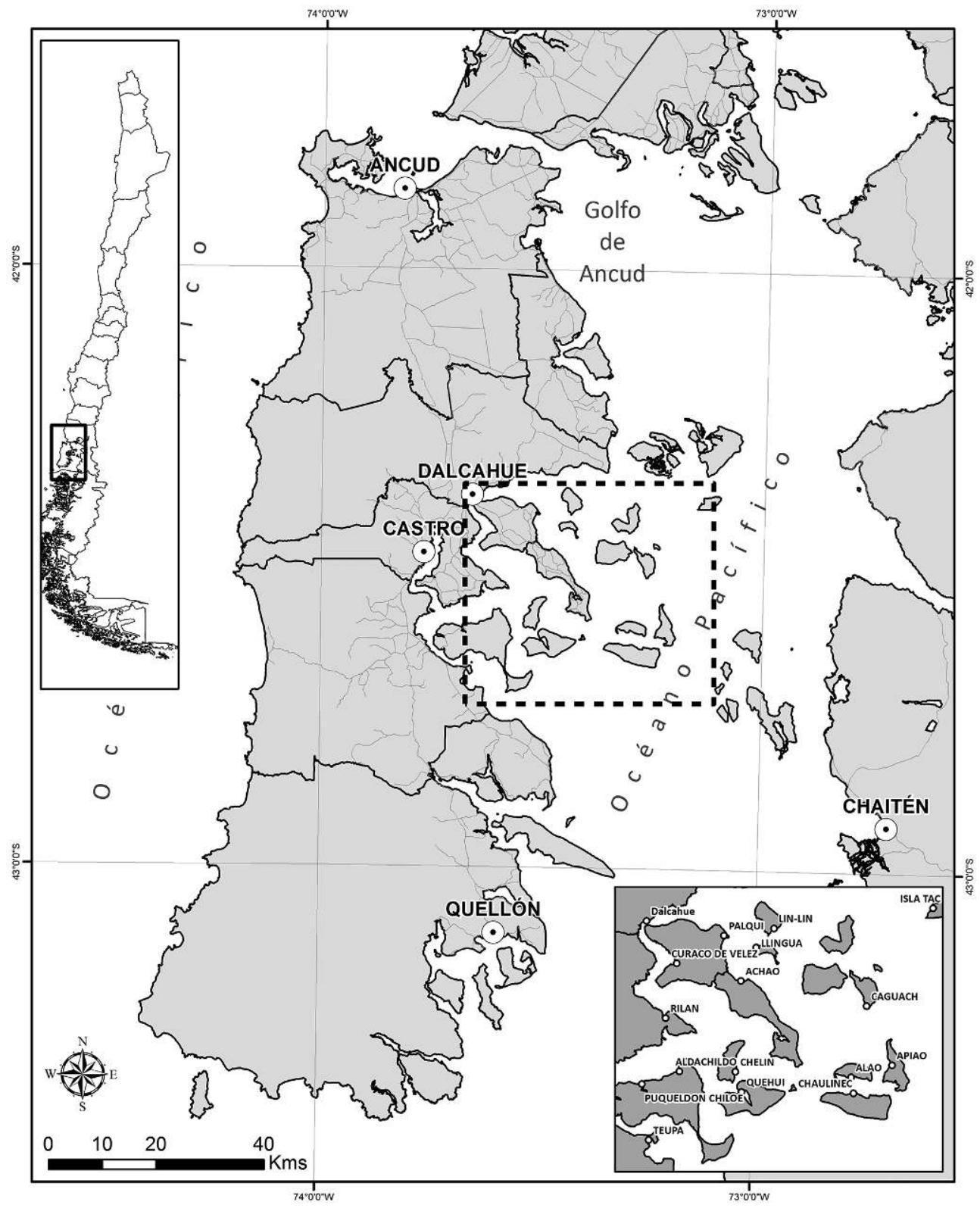

Figura 1 - Mapa del archipiélago de Quinchao. 
“etnografía móvil” (Watts y Urry 2008; Novoa 2015). Se trata de un “involucramiento co-presente" donde el investigador se mueve dentro de modos de movimiento y emplea un rango de observación y técnicas de registro.

Las observaciones que se hicieron ocurrieron de manera discontinua y flotante (Pétonnet 1982). Observamos, participamos y nos movemos con los sujetos estudiados, captando formas de habitar, relaciones y sentimientos de inmovilidad. En efecto, nos interesaba todo lo que tenía que ver con el uso del celular y la particularidad territorial (Miller y Slater 2001; Martínez 2006; Cucurella 1999; Ardévol y Lanzeni 2014) de las islas de Quinchao.

Bajo una pauta de preguntas fuimos estableciendo conversaciones y preguntas abiertas, desde una "entrevista en profundidad" (Valles 2003). Los dos jóvenes con los que estuvimos, y que se presentan en este artículo, vivían en las mismas casas de hospedaje donde nos quedamos. De este modo, las dinámicas etnográficas estuvieron ritmadas por sus quehaceres del día a día. Finalmente, el conjunto de las observaciones fue registrado en un "diario de campo" (Velazco y Díaz de la Rada 1997) para depurar el diseño investigativo e interpretativo.

\section{LA MOVILIDAD NEOLIBERAL EN EL ARCHIPIÉLAGO}

Partimos de la premisa que sostiene que el neoliberalismo en Chile se torna una episteme, que opera de forma técnica y que intenta volver la experiencia humana un reflejo de la economía (Ossa 2017). Por consiguiente, opera desde una "libertad negativa" (Galcerán 2009) con ausencia de restricciones, ligada al mercado, al emprendimiento personal, a sus propios deseos y temores (Ossa 2017: 21-23). En Chile, el progresismo post-dictadura no supera el neoliberalismo (Garretón 2012), sino que lo expande. Las fronteras ya no inmovilizan, sino que son formas de entrar y de acceder a una "nueva etapa de generación de plusvalía inmaterial" (Ossa 2017: 24), que independiza a los actores en la figura del "sujeto económico", desprendiéndolos de cualquier valor colectivo (Gough 2002).

En el caso del Archipiélago de Chiloé, es posible detectar la temprana instalación de diversos medios de comunicación. Primero, llegará la radio, luego, en la década de 1990, la televisión y el teléfono, para posteriormente, y hasta hoy, pasar al mundo tecnológico-digital de computadores, notebooks, tarjetas de crédito y MP3 (Lazo y Carvajal 2018). Se recibe con entusiasmo la llegada de los llamados "artefactos de la globalización" (Mattos 2006) como objetos que cambian el paisaje insular y la identidad chilota. En este sentido, cabe señalar el impacto que tiene la movilidad virtual en el presente siglo, siendo elementos claves la conexión "artificial" en espacios y tiempos que propenden a la comunicación y el viaje en sus diferentes formas (Urry 2000).

Desde el año 2007 los dispositivos tecnológicos tienden a incrementarse en la isla (Bacchiddu 2012), impactando en un nuevo modo de habitar e interactuar 
en el territorio. La modernización en Chiloé y el uso de objetos tecnológicos es bien recibido por las nuevas generaciones, pero chocan con la tradición aún imperante en el archipiélago y con otro tipo de prioridades, como salud y educación (Henríquez et al. 2015). Pese a lo anterior, las altas posibilidades de acceder a dispositivos celulares para la población chilena en comparación con el resto de Latinoamérica (Ureta 2008) hace que las tensiones descritas pasen a un segundo plano en la "neo cultura chilota" (Mansilla 2006).

La llegada del mall a Chiloé en el año 2012 deviene en la exhortación al crédito y el endeudamiento en la compra. Instala en la cotidianidad isleña una oferta de acceso e integración al espacio global, a sus formas de intercambio y transacción con tarjetas de crédito. Ese mismo año, se construye el aeropuerto Mocopulli, pudiéndose llegar desde la ciudad de Santiago de forma directa hasta la ciudad de Castro. De ese modo, el flujo (físico e informacional) de personas que pueden ingresar a la isla es mayor: ya no es necesario cruzar en ferry para entrar y salir de la isla, desplazamientos que operan como símbolos de la desaceleración y el aislamiento entre el continente (Baldacchino 2007) y la movilidad existente en Chiloé.

Lo anterior, aparejado a la pronta construcción de un puente que unirá la isla con el continente, se transforma en un flujo de capital en una sociedad de consumo de tipo isleño, junto con generar una restricción e insatisfacción que produce malestar en los jóvenes y trabajadores activos, un tipo específico de mal-estar entre su cuerpo y su alteridad dominada por el deseo (Rojas 2012) de productividad y consumo de la movilidad. Es una sensación que genera una inseguridad e incertidumbre (Beck 1986) y que habla de una relación fuerte entre un imaginario de inclusión que, desde su interior, produce y configura la exclusión subjetiva (Lapsos 2018) de los isleños.

No podemos dejar de mencionar que todo el desarrollo de las tecnologías, imágenes e imaginarios de la movilidad en Chiloé se da con fuerza luego de la industrialización acuícola desde la década de los 80. Como plantea Mansilla (2009), los centros de cultivo del salmón no sólo han alterado el paisaje marino y costero, sino que han también transformado la estructura social, al proletarizar a un campesino (Mansilla 2009). Se trata de un neoliberalismo o neocapitalismo regional, agro-exportador y extractivista, en donde "se disuelven las fronteras nacionales a favor de un proyecto global" (Vargas 2007: 82) que pone en el centro lo económico y sus diferentes formas de desarrollo cultural y consumo.

Específicamente, la productividad de la industria del salmón instala una fuerza de trabajo que abre fronteras a lugares de trabajos más urbanos y temporales (Gobantes 2011). Operarios y técnicos, entre flexibilidad laboral y emprendimiento profesional (Fløysand y Román 2008), pasan a ser "empresarios de sí mismos”, donde el capital flexible dirige el cuerpo y sus movimientos de trabajo (Pierbattisti 2010). 
En efecto, este tipo de procesos fue también produciendo una migración que desertificó muchas de las islas (Gobantes 2011), las que se empezaron a precarizar y a fragmentar comunitariamente, perdiendo su relación con la naturaleza, ya no produciendo su alimentación (Bravo 2004; Cárdenas 2009), así como replegándose en sus viviendas.

Otro de los síntomas de la consolidación del sistema neoliberal en el archipiélago es la llamada "gentrificación" (Glass 1964; Berry 1985; Clark et al. 2007). Se trata de un desplazamiento de los habitantes tradicionales, quienes pueden ser comprados mediante tratos atractivos por parte de gobiernos locales y privados. En la lógica del turismo sustentable y la postal chilota, se van instalando comercios, restaurantes y hostales boutiques. En paralelo, producto de los desplazamientos migratorios, van surgiendo periferias y exclusiones en los alrededores de centros urbanos como Castro, Ancud o Quellón (Barton et al. 2013).

Con respecto al plano energético, muchas islas del mar interior de Chiloé han sido recientemente electrificadas. En el caso de archipiélago de Quinchao, los trabajos terminaron el año 2016 e implicaron una modificación de las prácticas cotidianas, por ejemplo, de aquellas que antes servían para sortear las señales y las interrupciones del celular y el teléfono. El que no acceda a este plano económico, aún tendrá que esforzarse más para sobrellevar la vida y la movilidad desde un aislamiento geográfico. Es por eso que gubernamentalmente se ofrece la tecnología como movilidad, cuando también se trata de normalización económica-espacial de la empresa energética y telefónica. Lo anterior significa que, cuando se cargue el celular en la isla, será una espera productiva en tanto la conectividad ha sido mediada y ofrecida como posibilidad móvil para islas alejadas. Será también, como plantea Bacchiddu (2012: 15), un objeto y mercancía simbólica que servirá para no ser juzgados negativamente por gente que no es de la isla.

En este sentido, la luz es un hito importante para la vida isleña. Tal como plantea Sheller en otro contexto socio-geográfico, la energía implica la representación del sueño de la modernidad, en tanto fuente de velocidad (Sheller 2014) y movilidad. En ese sentido, el defecto histórico de la energía y aislamiento en estas islas es la posibilidad y deseo del consumo de los objetos, de sus imágenes y pantallas. Como plantea Santaella (2010: 72), por medio de la localización y la conexión, la experiencia del celular se transforma en un archivo de control y vigilancia económica/individual, donde la conexión y su intensidad permitirán mayor control e identificación. Todos estos elementos comienzan a invadir lentamente las islas y sus modos de habitar.

\section{Carlos: entre la estabilidad espacial y la (in)movilidad isleña}

El 2016 conocimos a Carlos, 27 años, y a su amistosa familia, en la alejada isla de Chaulinec. Un año después, en enero del 2017, en el contexto de la fiesta 
del Nazareno de Caguach, volvimos ahí luego de viajar en la Contanza Andrea. ${ }^{3}$ Ya desde el viaje en lancha se podían reconocer los mismos tripulantes que a su vez eran isleños y vecinos de Carlos. Ese año regresamos con otras preguntas y nos acercamos nuevamente.

En esta ocasión, la segunda en dos años, la sensación del viaje fue distinta, la incertidumbre era menor, conocíamos el camino y habíamos preguntado con anticipación sobre la disponibilidad de alojamiento. Luego de caminar unos 300 metros llegamos a la casa, y es Carlos, hombre de sonrisa afable, quien nos recibe y nos invita a tomar asiento en su cocina.

Carlos es un joven común de estas islas. Está ligado a actividades de trabajo o productivas asociadas al territorio, pero se conecta de forma natural con el mundo global. Es hijo de la señora Magdalena (de unos 50 años), quien tiene una casa de hospedaje en la isla. Este joven se encarga de la camioneta, de hacer todo tipo de "fletes" y encargos. ${ }^{4}$ Prácticamente aquí no hay vehículos ni gestos visibles de velocidad. Carlos además tiene una pequeña lancha, donde cruza gente u objetos desde Alao y Apiao hasta Chequian, en la isla de Quinchao. ${ }^{5}$ Su familia es un poco diferente, ya que al dedicarse al turismo, tienen una situación económica más acomodada que el resto de los habitantes, lo que hace que Carlos, a primera vista y por ahora, nos diga que no tiene deseos de migrar.

A nuestra llegada están en la casa Magdalena y Carlos, además de una familia proveniente de la ciudad de Calama (Norte de Chile) que se hospedaba por vacaciones ahí. El padre de la familia, Miguel (de unos 50 años), está en algún lugar del archipiélago, de paseo y viendo un partido de la selección de Chile. Muchas veces las mujeres de estas islas tienen que esperar en la intimidad y productividad de la casa el regreso de los que salieron. De cualquier modo, entre Magdalena y Carlos se las "arreglan" para compartir el quehacer de la casa, en donde se mezcla la vida singular de la familia y los visitantes o turistas.

Habitan una casa común no precarizada, de clase media y rural, donde hay un patio de tierra, terminaciones de madera y piezas en desuso de los hijos mayores que ya se fueron.

Tienen una cocina con "salamandra", como se utiliza en el sur de Chile, donde acontecen los momentos más importantes del día, como tomar el "mate" temprano, conversar en torno al día que empieza o sobre el viaje que

3 La fiesta del Nazareno de Caguach es una fiesta religiosa celebrada desde la época colonial (siglo XVIII) en la isla, en honor de la imagen del Cristo Nazareno. En el mar interior de Chiloé, se suele nombrar a las embarcaciones con nombres de mujeres, en el entendido de que el mar es "La mar", que es femenina y que representa a las mujeres en el estereotipo cultural de lo sensible e inestable.

4 Hacer "fletes" es un servicio informal donde se trasladan objetos, mercaderías y personas.

5 Chequian es la localidad más cercana para cruzar y llegar hasta Achao, en un micro que pasa una vez al día. Por Chequian es por donde también se cruzan, vía ferry, automóviles a las islas o viceversa. 
vendrá. ${ }^{6}$ Frente a la mesa, en el espacio de la cocina tradicional, está la televisión siempre prendida, como objeto primordial y de conexión con el afuera. Aquí, a pesar de tener instalados servicios de televisión por cable, se redunda en la programación nacional, en las telenovelas, en las noticias, en los matinales, en los "shows televisivos" de la tarde y de la noche. Desde aquí, se establece una forma familiar de consumir estos discursos y publicidades que vienen del continente.

Esta familia tiene contacto fluido con el exterior gracias a sus dispositivos celulares, y cada vez van un poco más allá. En este contexto, ya no sólo se trata del consumo del objeto en su variante conectiva-telefónica, sino que ahora es también un dispositivo que se ensambla en sus cuerpos y delimita el habitar los espacios. Al conversar con Carlos observamos que él está con el celular en la mano, interactuando con su tecnología y con nosotros al mismo tiempo.

Magdalena nos cuenta que ella hace poco tiene un celular "que se toca" (touch). Ella no es tan dependiente de su celular, lo deja a menudo en los muebles de su cocina, no habla ni la llaman mucho; por lo mismo, no lo revisa tan seguido. Sin embargo, su celular luce una hermosa carcasa rosada, llamativa, que da cuenta de cómo este objeto tiene un valor e identidad. El celular es para ella más funcional, persiste y vive en el anclaje territorial que ella experimenta pues no representa un objeto que la mueva hacia otros territorios desconocidos. Hay factores generacionales y de edad en esta relación. Con la ayuda de su hijo, el celular de Magdalena se transforma en una tecnología que moviliza gente hacia su casa de hospedaje pues tiene una cuenta de Facebook a su nombre donde la publicita.

Para los miembros de esta familia, el celular, en su variante telefónica y desde el WhatsApp, sirve para la gestión y traslado de objetos y mercaderías. El WhatsApp "siempre llega", a diferencia de las embarcaciones (lanchas) o servicios (municipales y gubernamentales), que siempre están a la espera de su "ronda", como sucede en el caso de la salud. ${ }^{7}$

Carlos es hermético, callado, silencioso. Se podría decir que se trata de un hermetismo muy juvenil, muy propio de quién crece y se identifica desde la proximidad de estos objetos. Al celular, lo sitúa como un objeto fundamental en la actualidad de su vida en la isla de Chaulinec. Observamos cómo su relación con el celular se desarrolla constantemente en la movilidad y en sus viajes de trabajo. Él ocupa las apps geo-satelitales del celular para poder conocer las rutas de la navegación (Navionics), el clima (Freemeteo) y las vías terrestres (Chequian) por medio de Waze. Esto da cuenta de un saber situado en torno

6 La "salamandra" es un sistema a leña de calefacción de la cocina hacia toda la casa y que además sirve para cocinar. La yerba "mate" se toma por infusión, es de sabor amargo y genera reunión. En Chiloé se instala culturalmente debido a las migraciones a la Patagonia chileno-argentina.

7 "La ronda" de salud corresponde al traslado de profesionales en ferry, de forma distribuida para todas las islas de la comuna, con una frecuencia de dos días a la semana. 
a las condiciones ambientales y de movilidad isleña. Carlos también es un asiduo usuario de Facebook y WhatsApp como forma de conectarse con gente de otras islas, y también con familiares, amigos y pareja. Para él, la tecnología acorta las distancias desde su propia isla en adelante, es decir, desde el pueblo de Achao hasta puntos más urbanos de la isla, como Castro o Ancud.

En efecto, luego de la electrificación en estas islas, es posible ver cómo toda la materialidad tecnológica llegó con rapidez a la juventud de las islas. Carlos nos cuenta que esperaron con ansias la llegada de la luz y su consumo energético, como una forma de aceleración y aproximación constante a una movilidad que venía de afuera de la isla. Su familia, antes del motor eléctrico, pasó por el lento proceso del desarrollo e inserción de la tecnología; desde la vela en la época que no había luz, pasando por la ampolleta "petromax" que permitía tener luz en las noches. El proceso de iluminación se completa en la actualidad con la luz de la pantalla de dispositivos móviles, como forma de energía expresada desde la electricidad que estos objetos necesitan. La carga eléctrica del dispositivo es una forma de espera para el consumo de la movilidad digital/física.

Carlos no se siente o percibe aislado. Habla con soltura de vecinos de otras islas, a pesar de que no los ve con mucha frecuencia. Ello se condice con lo planteado por algunos de sus amigos en Chaulinec, para quienes "las distancias se han acortado" con las tecnologías. Ahora logran relacionarse con otros territorios donde antes era imposible hacerlo (fuera del archipiélago de Quinchao).

En efecto, lo anterior marca una pauta de normalidad y de nula extrañeza en relación con los dispositivos que se refleja en Carlos y en cómo se refiere a ellos como algo natural, sabido, compacto y propio. Es, en sí mismo, una forma de entretención que le ayuda a pasar el tiempo de manera menos pausada, ligera e impropia que en la isla - una forma de espera controlada entre una salida y una localidad simultánea.

Carlos tiene ahora una nueva lancha (algo así como un auto en la ciudad) y cruza gente por la suma de 40 mil pesos (unos 57 euros). Está conforme con eso y, a sus 27 años, no tiene planes para poder salir. El celular e Internet, sumado a su trabajo y estabilidad, deja en él cierto conformismo que se traduce en anclaje. Es asiduo a las "tecnologías móviles" y lo complementa con la televisión por cable como tecnología que promueve, mediatiza y hace publicidad de un mundo conectado. El televisor, el "plasma", está situado en diferentes partes de la casa: frente al comedor, en la cocina y en su dormitorio. Así mismo, el consumo de noticias nacionales y las teleseries son fundamentales para muchos isleños, al mostrar lo actualizado de un territorio al que no pertenecen, pero al que tienen acceso.

Para Carlos, el uso y consumo del celular muestra una dicotomía. Por un lado, vive entre interacciones e imaginarios modernos y continentales. Por otro lado, mantiene una vida isleña diagramada desde la lentitud y la baja 
interacción social. Aquí no hay discursos de incertidumbre o incomodidad, sino más bien de pasividad y resignación. Habita entre la tecnología digital y lo análogo que aún persiste en interacciones y emplazamientos singulares, en una espacialidad intermedia entre muchos lugares e imágenes que se deben consumir y conectar para poder seguir en la isla y no pensar en migrar físicamente de manera inmediata. En una isla donde aparece la espera "por salir", emerge la relación entre Carlos y su celular atravesada por la agencia, flujos, intensidades y energías de aceleración que relativizan el malestar posible.

\section{Sergito y Ariel: entre el "mal-estar", la incertidumbre móvil y el consumo tecnológico}

El 2016 conocimos la isla de Alao. Informados sobre una familia que prestaba alojamiento, recurrimos a ellos y aprovechamos de conocer la realidad isleña desde ese mismo contexto. El 2017, ya establecida la confianza, nos comunicamos por teléfono con María, 55 años, la madre de la familia, para avisarle de nuestra nueva visita. Esta vez ya no tendríamos que dormir en la casa de hospedaje, sino que en una inmediación de su casa. María había habilitado ahí unas piezas que estaban conectadas con la casa misma, lo que nos daba la posibilidad de interactuar más adentro, en la cocina-comedor, que es el centro de reuniones familiares y sociales.

Fue Juan, 55 años y padre de la familia, quien nos recibió en la casa y nos dejó ahí, en la cocina-comedor, mientras regresaba al trabajo. El dejó la TV prendida antes de irse, como forma de cortesía y para dejarnos "en presencia de algo exterior". A los minutos llegó uno de los dos hijos, "Sergito" (27 años), nos saludamos, recordamos, para luego poner la "tetera" y servirnos algo caliente.

Lo primero que nos cuenta Sergito es el acontecimiento de la llegada de la antena de telefonía celular Entel: "Ahora la red llega a toda la isla. Ya no es necesario de ubicaciones especiales y hacer maniobras específicas para tener la señal”. Se sienten más tranquilos, más conectados, nos dice. Cuentan ahora con Internet, con un plan de DirecTV. También, como en Chaulinec, ahora tienen una "Caja vecina" para poder pagar las cuentas y poder retirar dinero. ${ }^{8}$ El viaje en lancha de antaño ya no es necesario para realizar este tipo de trámites, la transacción económica se puede hacer desde el lugar propio ayudados por la tecnología.

María (la mamá), tiene WhatsApp de un celular que comparte con su marido. El uso de este dispositivo se da principalmente para actividades laborales y familiares (hospedaje y negocio). Sin embargo, ella está a la espera de que sus hijos prontamente le hagan una cuenta de Facebook para publicitar

8 La "Caja vecina" es una plataforma del Banco del Estado chileno, donde es posible extraer dinero de "cuentas rut"; cargar teléfonos; pagar planes, cuotas, envíos. De otra parte, DirecTV, empresa de televisión, aún no se puede pagar desde la "Caja vecina” y se debe pagar en Castro. 
su hospedaje, negocio y otras actividades. Juan, en cambio, está en un grupo de WhatsApp de la corporación de salud donde trabaja. Cuando lo visitamos, lo vimos escribiendo y preguntando por personas o pacientes, optimizando el tiempo de trabajo a partir de la tecnología. María también ocupa esta aplicación para hablar con su hija mayor, que migró a otra región del Sur para trabajar como profesora en un colegio.

Volviendo a los hijos, Ariel y Sergito, observamos que pasan gran tiempo en la cocina de la casa junto a sus celulares y viendo televisión, entre otras actividades. ${ }^{9}$ Ariel, 18 años, estudia en el internado Ramón Freire, ubicado en el pueblo de Achao. Valora su estadía en el internado como forma de no estar en la isla. No tiene amigos en Alao y prefiere estar en la rutina del internado, donde hay más acceso a una vida "más juvenil". Aquí, él puede intercambiar o relacionarse con jóvenes de su edad y distinto sexo, lo que no sucede en su isla. Sergito, en cambio, es técnico-profesional cesante que busca trabajo en Castro o algún lugar urbano de la isla. Para él, migrar es una necesidad imperiosa, pues ya ha vivido en otras ciudades urbanas del Sur de Chile, como Temuco y Aysén. El ritmo de vida que lleva en la isla es insuficiente y lento para él. Las ganas de migrar se transforman en una forma de espera constante.

En la época que los visitamos era verano y estaban de vacaciones en la casa. Cuando no están en casa, estos jóvenes realizan labores de flete, cortan leña o hacen diversas gestiones con la camioneta que poseen. En los momentos que tienen juntos, es frecuente verlos usando el celular y compartiendo fotos, "memes" y noticias en las redes sociales. Sin embargo, pueden pasar un buen rato en que están cerca, pero no se hablan debido a que están observando o escribiendo en el celular. Interactúan desde ahí, desde el silencio con los demás que no están conectados. Están tan sólo con su presencia, pero ubicados o desplazados hacia otro lugar que no es Alao, que está en el Chiloé urbano o en el Chile continental. Es en este espacio de interior donde estas relaciones, actualizaciones y aproximaciones se incrementan.

Conversamos en torno a las formas de comunicarse con sus contactos. Ariel se comunicaba por WhatsApp y de esa forma podía mantener actualizadas amistades y los tiempos de espera para concretarlas. Son tecnologías que movilizan información y presencia. Como nos cuenta Ariel, las islas como Alao, Chaulinec y Apiao no son puntos de encuentro entre amistades que viven separadas por toda la extensión de Chiloé. Las redes sociales y apps son la forma actual de estar e intercambiar, privilegiando lo virtual por sobre lo físico. Los lugares de encuentro y las festividades al interior de las islas han desaparecido; las formas de encuentro se dan en la tecnología o en los viajes a las ciudades más urbanas, como Castro.

9 En las casas del Sur de Chile, la cocina es un espacio de alta interacción. La vida social de las familias transcurre generalmente ahí. 
Las maneras de habitar desde las tecnologías se interrumpen con el quehacer isleño tradicional. Ese día, al poco tiempo que llegamos, ellos se van al patio a trabajar en madera, haciendo usleros (utensilio de cocina para estirar masas). Cortan leña y ambos hacen fletes. En esos instantes, dejan el celular de lado unos minutos y se despreocupan hasta que terminan sus quehaceres. Luego vienen los fletes, como parte de su trabajo diario, de unas tres "carreras" ${ }^{10}$ entre el muelle y la localidad de destino, pudiendo durar una hora como máximo. No es mucho tiempo ocupado. Ambos jóvenes parecen estar constantemente aguardando nuevas acciones: se espera la llamada telefónica; alguna señal por el chat; el aviso de algún familiar en el muelle.

Todavía no hay 4G, pero existe una sensación optimista de su arribo. Ellos tienen un plan de pago para el wifi que incluye llamadas para la casa (teléfono fijo) y televisión por cable. Además, estos jóvenes tienen en sus dispositivos Internet portátil, que les permite estar conectados en cualquier punto de la isla, a diferencia del año anterior. Sin estos servicios y contrataciones, sería imposible mantener a estos jóvenes realizando alguna función de ayuda familiar en la isla.

En la noche, Sergito nos dice que no es posible vivir ahí. Que si fuera por él viviría en Castro, ciudad más cercana, en donde hay todo lo necesario y la ruralidad desaparece. Sus intercambios afuera de la isla los realiza por medio del WhatsApp. Conoce a los otros jóvenes con los que estuvimos en Chaulinec. Como sucede en las ciudades, los siente próximos porque están al frente, a pesar de que no los ve casi nunca ni tenga contacto físico con ellos. La espera y la búsqueda de trabajo se acrecientan para él. Sobre todo, cuando la movilidad en lancha no es expedita ni continua. Esta contradicción le genera un malestar con el lugar en donde vive, así como con el territorio en donde espera migrar.

$\mathrm{Al}$ día siguiente acompañamos a Ariel, el otro hermano a hacer un pago a la "Caja vecina" del sector de "Miraflores". Para realizar el trámite viajamos en su camioneta. Va a pagar unos audífonos que había comprado por Internet en una multitienda de Santiago. Le costaron 12 mil pesos (unos 17 euros) y tenía que retirarlos en el "Chilexpress" del pueblo de Achao, dado que el servicio llega tan sólo hasta ahí. ${ }^{11}$

En el internado le queda el último año y dice que, si fuera por él, repetiría otra vez para no salir y replegarse en la isla. Ariel, sin embargo, no revisa el celular de forma tan frecuente, pero ese es de gran importancia en su vida y aspiraciones. Con el celular puede, por ejemplo, bajar discos de música (bajó uno durante ese día). Hay un sentimiento de desinterés en sus palabras que

10 Se entiende por "carreras" el desplazamiento de un lugar a otro en varios tipos de transporte y de carga.

11 Chilexpress es un servicio de envío de encomiendas, documentos o dinero, por vía terrestre, avión o de forma digital, a Chile y el extranjero. 
tiene relación con que, para salir de la isla, a la edad que él tiene, necesita de una inversión familiar que lo lleve a estudiar o trabajar afuera.

Dentro de la misma tarde, acompañamos a Ariel y Sergito a pelar habas en el comedor de la casa para la comida de la noche. María había traído bastante de Achao y era necesario pelarlas todas. ${ }^{12}$ Mientras las pelábamos, conversábamos y Ariel veía en Internet, vía Google, como se preparaban y cocían. Mientras cocinaban, estaban pendientes del almuerzo, que era arroz, longaniza y huevos. Además, ellos son los encargados del almacén familiar que está en la misma casa.

Para esta familia, el celular y el WhatsApp son fundamentales en la organización de lo cotidiano. Cuando las lanchas van llegando, la isla se moviliza a partir de las comunicaciones que se despliegan para el flete de cargas. También se movilizan a partir de los bueyes de carga que llegan al muelle. Tales coordinaciones son prácticas de movilidad y dan cuenta de la vida en una isla, en donde los jóvenes pueden desenvolverse sin problemas entre dos mundos o modos de habitar. Para Sergio y Ariel, la vida sigue y el trabajo familiar se realiza de forma mecánica, desinteresada, y sin atribuirle un valor de progreso. Viven una actualidad en donde saben que no avanzan ni salen, estando en el desfase entre la vida en la isla y la vida de afuera. La movilidad, desde lo inmóvil aquí, se desarrolla de forma intensa en su gestión, pero se confunde con el deseo consumista de las tecnologías que les comunican el mundo que aspiran.

\section{CONCLUSIONES: INMOVILIDAD Y MALESTAR EN CHILOÉ, O EL DISPOSITIVO COMO FORMA DE SORTEAR LA FRICCIÓN DEL ESTAR AHÍ}

El uso de tecnologías cada vez más cercanas a la experiencia y a la relación espacial tiene también relación con la historia y geografía de los territorios. En este sentido, concordamos con el diagnostico de Castells (2001) respecto a la instauración de una sociedad de red donde Internet permite nuevas formas de relación social, constituyéndose en un medio de comunicación que organiza la vida social.

En el caso de Chiloé, y su rápida integración con la modernidad, esto se demuestra en la relación estrecha que se ejerce desde la espera e inmovilidad de los jóvenes - una lentitud que, en tanto no dialéctica como dice Bissell (2007), se amortigua y convive desde una relación múltiple con los objetos y en particular desde el smarthphone. Los jóvenes desde ahí se anticipan y movilizan como gesto integrativo al territorio neoliberal y global que, en el caso de ellos, empieza desde Achao en adelante. Pero este territorio o lugar económico trae consigo, en forma inmanente, líneas fronterizas entre integración y exclusión de quienes pueden, o no, habitar ese espacio. 
De aquel modo, si la migración patagónica comportaba un gesto productivo y de progreso (masculino) ante una necesidad de subsistencia (Lazo y Carvajal 2018), con la entrada de la industria acuícola esto se profundiza y a grandes rasgos deja sus efectos en una cultura del movimiento que demanda productividad. Sin embargo, en la actualidad, con una industria acuícola en retirada, que opera cada vez con menos trabajadores humanos, la oferta local de trabajo se reduce y no todos los jóvenes pueden acceder a un trabajo cercano. ${ }^{13}$ Esto hace que muchos que se encuentren desempleados deban permanecer en sus islas, incluso luego de haber salido a estudiar (Puga 201 l).

Es así como, en defecto de lo anterior, los jóvenes en el contexto de resignación, espera e inmovilidad territorial pueden, e intentan, ser productivos en el plano del consumo de una modernidad de la cual logran ser espectadores, sintiéndose parte de la realidad social. No obstante, y como plantea Ureta (2008), esta posibilidad móvil y publicitaria del celular sería signo de su propia exclusión e inmovilidad territorial. Esa exclusión es evidente en las islas y aún más compleja cuando por, medio del celular, se instala una nueva forma de habitar que produce el malestar de no sentirse ni integrado ni excluido, ni rural ni urbano territorialmente, entre el confort, el deseo y la táctica.

En los casos analizados, vemos cómo el uso de la tecnología produciría un tipo de "mal-estar" (Rojas 2012), en tanto reproduce la percepción de un habitar y encarna lo "liminar" (Turner 1980). Esta condición, de tipo geográfico y fronterizo, instala la inseguridad y desorientación sobre el porvenir individual en los jóvenes isleños. De ahí que los imaginarios de movilidad y migración (Salazar 2011) estén gobernados por aquel lugar que anhelan, pero no saben con certeza cuál puede ser dentro del Sur.

El consumo de las tecnologías y el smarthphone operan como un tipo de práctica móvil e integrativa, de salida o avance; sin embargo, lo es tan sólo en su posibilidad perceptiva e imaginaria. En ese sentido, la movilidad cotidiana, vista aquí desde la inmovilidad, puede ser también, como plantea Jouffe (2011), una práctica de clase que aspira a un territorio e imaginario que se valoriza a diario desde la televisión en adelante. Es una movilidad que aspira a un territorio ordenado y que asegure menor fricción.

De esta manera, el uso del celular parece despolitizar la condición de incomodidad e incertidumbre que les provoca pensar que el tiempo avanza sin poder migrar. Esto se visibiliza y experimenta en distintos grados. Alao, en tanto isla, tiene menos proyecciones de desarrollo en la actualidad, se muestra como un territorio que para los jóvenes no genera ningún deseo de habitar, dado que ahí hay nulos lazos y gestualidad juvenil. En Chaulinec, el panorama

13 Según datos del INE (2016), uno de los factores que ha influido fuertemente en el desempleo regional ha sido el desempleo producido desde la industria acuícola. Ese rubro mostró 8690 trabajadores menos (INE 2016). 
no es muy diferente; sin embargo, se denota un mayor grado de desarrollo a nivel comunitario. Lo que hace que, dependiendo del joven, la familia y sus recursos, aún queden expectativas de seguir ahí, más allá de la exclusión presente. En este contexto, el smartphone en ambos casos será fundamental pero problemático, dado que en su constante actualización se instala también el lugar y la localización controlada del consumo, como modo de dominación por medio de la movilidad.

\section{BIBLIOGRAFÍA}

APPADURAI, Arjun, 2001, La Modernidad Desbordada: Dimensiones Culturales de la Globalización. Buenos Aires, FCE.

ARANCIBIA, Juan Pablo, 2002, “La mediatización de la política”, Comunicación y Medios, 13 : 185-202.

ARDÉVOL, Elisenda, y Débora LANZENI, 2014, "Visualidades y materialidades de lo digital: caminos desde la antropología”, Antropológica, 32: 11-38.

BACCHIDDU, Giovanna, 2012, "Changing values: mobile phones and soft drinks in Apiao, Chiloé, Southern Chile”, ponencia presentada en el 54. ${ }^{\circ}$ Congreso Internacional de Americanistas: "Construyendo Diálogos en las Américas", Viena.

BALDACCHINO, Godfrey, 2007, "Fixed links and the engagement of islandness: reviewing the impact of the Confederation Bridge", The Canadian Geographe/Le géographe canadien, 51: 323-336.

BARTON, Jonathan, et al., 2013, "Reestructuración urbana de un territorio glocalizado: una caracterización del crecimiento orgánico en las ciudades de Chiloé, 1979-2008”, Revista de Geografía Norte Grande, 56: 121-142.

BAUMAN, Zigmunt, 1999, La Globalización: Consecuencias Humanas. México, DF, FCE.

BAUMAN, Zigmunt, 2003, La Modernidad Liquida. México, DF, FCE.

BECK, Ulrich, 1986, La Sociedad del Riesgo: Hacia Una Nueva Modernidad. Barcelona, Paidós. BERRY, Brian, 1985, "Islands of renewal in seas of decay", en P.E. Peterson (comp.), The New Urban Reality. Washington, DC, Brookings, 69-96.

BISSELL, David, 2007, “Animating suspension: waiting for mobilities”, Mobilities, 2: 277-298. BRAVO, José, 2004, La Cultura Chilota y Su Expresión Territorial en el Contexto de la Globalización de la Economía, Departamento de Geografía, Universidad de Chile, memoria para optar al título profesional de geógrafo.

CAMPOS, Luis, y Miguel Angel AGUILAR, 2015, "L'expérience corporelle de l'attente dans les déplacements en métro”, Sociétés, mobilités, déplacements, 9: 158-168.

CÁRDENAS, Renato, 2009, “Las salmoneras provocaron en Chiloé un impacto mayor que la conquista: entrevista de Rosario Mena a Renato Cárdenas”, en Nuestro.cl: Patrimonio Cultural de Chile, disponible en < https://patrimonio.cl/archivo/las-salmoneras-provocar on-chiloe-impacto-mayor-la-conquista/ > (última consultación en diciembre del 2019). 
CASTELlS, Manuel, 1994, "Flujos, redes e identidades: una teoría crítica de la sociedad informacional”, en Manuel Castells et al. (comps.), Nuevas Perspectivas Críticas en Educación. Barcelona, Paidós, 13-54.

CASTELlS, Manuel, 1996, La Era de la Información: Economía, Sociedad y Cultura, vol. 1: La Sociedad Red. Madrid, Alianza.

CASTELLS, Manuel, 2001, "Internet y la sociedad red", La Factoría, 14-15, disponible en $<$ https://revistalafactoria.org/articulos/2018/6/4/internet-y-la-sociedad-red > (últimaconsultación en diciembre del 2019).

CLARK, Eric, et al., 2007, "Island gentrification and space wars”, en G. Baldacchino (comp.), A World of Islands: An Island Studies Reader. Charlottetown, Institute of Island Studies, University of Prince Edward Island, 481-510.

CRESSWELL, Tim, 2010, "La política de la turbulencia", en G. Beiguelman y J. La Ferla (comps.), Nomadismos Tecnológicos: Dispositivos Móviles, Usos Masivos y Prácticas Artísticas. Madrid, Ariel, 39-48.

CUCURELlA, Leonela, 1999, Antropología del Ciberespacio. Quito, Ediciones Abya-Yala.

DURSTON, John, 2001, El Capital Social en la Gestión del Desarrollo Rural: Díadas, Equipos, Puentes y Escaleras. Documento de trabajo de la Comisión Económica de América Latina CEPAL, 15, disponible en < https://repositorio.cepal.org/bitstream/handle/1 1362/2346/1/ S2002033_es.pdf > (última consultación en diciembre de 2019).

FFRENCH-DAVIS, Ricardo, 2001 , Entre el Neoliberalismo y el Crecimiento con Equidad: Tres Décadas de Política Económica en Chile. Santiago, Dolmen Ediciones.

FLØYSAND, Arnt, y Álvaro ROMÁN, 2008, "Industria salmonera, sistemas de innovación y desarrollo local: el punto de vista de las municipalidades de Chiloé”, informe del proyecto "The Spatial Embeddedness of Foreign Direct Investment", Bergen, Departamento de Geografía de la Universidad de Bergen.

GALCERÁN, Monserrat, 2009, Deseo (y) Libertad. Madrid, Traficantes de Sueños.

GARRETÓn, Manuel, 2012, Neoliberalismo Corregido y Progresismo Limitado: Los Gobiernos de la Concertación en Chile, 1990-2010. Santiago de Chile, Editorial Arcis y Ediciones Clacso.

GLASS, Ruth, 1964, Aspects of Change in London. Londres, University Centre for Urban Studies. GOBANTES, Catalina, 2011 , Migraciones Laborales en Un Archipiélago en Transformación: Chiloé ante al Desarrollo de la Salmonicultura. Santiago, Universidad de Chile, tesis de grado en Antropología Social.

GOUGH, Jamie, 2002, "Neoliberalism and socialisation in the contemporary city: opposites, complements and instabilities", Antipode, 34: 405-426.

GRENIER, Philippe, 1984, "Chiloé et les chilotes, marginalité et dépendance en Patagonie chilienne”, Annales de géographie, 525: 624-626.

HENRÍQUeZ, Cristina, et al., 2015, Primera Encuesta Provincial CESCH: Chiloé y Sus Prioridades. Chiloé, Centro de Estudios Sociales de Chiloé, disponible en < https://www.territoriocesch.com/general-1/iad6zwee 17/Primera-Encuesta-Provincial-CESCH-CHILO \%C3\%89-Y-SUS-PRIORIDADES > (última consultación en diciembre del 2019).

INE - Instituto Nacional de Estadísticas de Chile, 2002, "Censo 2002: Región de los Lagos", disponible en < http://www.ineloslagos.cl/app/bancodatos/bancodatos.htm > (últimaconsultación en diciembre del 2019).

INE - Instituto Nacional de Estadísticas de Chile, 2016, "Indicadores de empleo 2016", disponible en < http://www.ineloslagos.cl/contenido.aspx?id_contenido $=80>$ (última consultación en diciembre del 2019). 
JOUFFE, Yves, 2011 , "Las clases socio-territoriales entre movilidad metropolitana y repliegue barrial: ¿Tienen los pobladores pobres una movilidad de clase?”, Revista Transporte y Territorio, 4: 84-117.

LAPSOS - Laboratorio transdiciplinar en prácticas sociales y subjetividad, 2018, "Salud mental y corporalidad", disponible en < http://www.lapsos.cl/laboratorio/salud-mentaly-corporalidad/ > (última consultación en diciembre del 2019).

LATOUR, Bruno 2005, Reassembling the Social: An Introduction to Actor-Network-Theory. Oxford y Nueva York, Oxford University Press.

LAZO, Alejandra, y Diego CARVAJAL, 2018, "La movilidad y el habitar chilote: cambios, rupturas y continuidades en las prácticas de movilidad cotidiana de los habitantes del archipiélago de Chiloé, en el sur Austral de Chile", Revista de Antropología Chungará, 50 (1): 145-154.

LAZO, Alejandra, y Francisco THER, 2014, "L'univers du voyage: géographie materielle et sensorielle des mobilités dans les iles de l'archipel de Quinchao, Chiloé, Chili”, Géographie et Cultures, 91-92: 45-54.

LEMOS, André, 2010, "Cultura de la movilidad", en G. Beiguelman y J. La Ferla (comps.), Nomadismos Tecnológicos: Dispositivos Móviles, Usos Masivos y Prácticas Artísticas. Madrid, Ariel, 1-11.

MANSILLA, Sergio, 2006, "Chiloé y los dilemas de su identidad cultural ante el modelo neoliberal chileno: la visión de los artistas e intelectuales”, Alpha, 23: 9-36.

MANSILLA, Sergio, 2009, "Mutaciones culturales de Chiloé: los mitos y las leyendas en la modernidad neoliberal isleña”, Convergencia: Revista de Ciencias Sociales, 51: 271-299.

MARTÍNEZ, Betty, 2006, Homo Digitalis: Etnografía de la Cibercultura. Bogotá, Uniandes.

MASSUMI, Brian, 1995, “The autonomy of affect”, Cultural Critique, 31: 83-109.

MATTOS, Carlos A. de, 2006, "Modernización capitalista y transformación metropolitana en América Latina: cinco tendencias constitutivas”, en A. I. G. Lemos, M. Arroyo y M.L. Silveira (comps.), América Latina: Cidade, Campo e Turismo. São Paulo, Clacso, 41-73.

MILLER, Daniel, y Don SLATER, 2001, The Internet: An Ethnographic Approach. Nueva York, Editorial Berg.

MORALES, Cristian, 2011 , "Luga: al alga moderna, el plástico marino", Synergies Chili, 7: 181-196.

NOVOA, André, 2015, "Mobile ethnography: emergence, techniques and its importance to geography”, Human Geographies, 9 (1): 97-107.

OSSA, Carlos, 2017, El Ego Explotado: Capitalismo Cognitivo y Precarización de la Creatividad. Santiago, Ediciones Facultad de Artes, Universidad de Chile.

PÉTONNET, Colette, 1982, "L'observation flottante: l'exemple d'un cimetière parisien", L'Homme, 22 (4): 37-47.

PIERBATTISTI, Damián, 2010, "Marx, Foucault y la biopolítica: la población como efecto de la ley de acumulación capitalista”, en I. Cassigoli y M. Sobarzo (comps.), Biopolíticas del Sur. Santiago, Editorial Arcis, 67-82.

PIRELA, Alexis, 2001, "La ética de la desaparición y ciudad en Paul Virilio", Utopía y Praxis Latinoamericana, 15: 100-107.

PUGA, Ismael, 2011 , “Escuela y estratificación social en Chile: ¿cuál es el rol de la municipalización y la educación particular subvencionada en la reproducción de la desigualdad social?", Estudios Pedagógicos, 37 (2): 213-232. 
ROJAS, Sergio, 2012, “La experiencia agotada: la tarea de subjetivar la desilusión”, conferencia en Coloquio Internacional "Malestar y Destinos el Malestar", Universidad de Chile. SALAZAR, Noel, 2011, "The power of the imagination in transnational mobilities", Identities: Global Studies in Culture and Power, 18 (6): 576-598.

SALAZAR, Noel, 2013, "Imagining mobility at the 'end of the world' ", History and Anthropology, 24 (2): 233-252.

SANTAELLA, Lucia, 2010, "Las ambivalencias de los medios móviles y locativos", en G. Beiguelman y J. La Ferla (comps.), Nomadismos Tecnológicos: Dispositivos Móviles, Usos Masivos y Prácticas Artísticas. Madrid, Ariel, 7 1-80.

SHELler, Mimi, 2014, Aluminium Dreams: The Making of Light Modernity. Londres, MIT Press.

SHELLER, Mimi, y John URRY, 2006, “The new mobilities paradigm”, Environment and Planning A, 38 (2): 207-226.

TIRONI RODÓ, Manuel, 2009, “Tecnologías múltiples, infraestructuras liquidas: sobre la performatividad de una autopista urbana”, en M. Tironi Rodó y F. Pérez Oyarzún (comps.), SCL: Espacios, Prácticas y Cultura Urbana. Santiago, Ediciones ARQ, 190-205.

TURNER, Víctor, 1980. La Selva de los Símbolos. Madrid, Siglo XXI.

URETA, Sebastián, 2008, "Mobilising poverty? Mobile phone use and everyday spatial mobility among low income population in Santiago, Chile", The Information Society, 24 (2): 83-92.

URRY, John, 2000, Sociology Beyond Societies: Mobilities for the Twenty-First Century. Londres, Routledge.

VALLES, Miguel S., 2003, Técnicas Cualitativas de Investigación Social. Madrid, Editorial Síntesis.

VANNINI, Phillip, 2011 a, "Performing elusive mobilities: ritualization, play, and the drama of scheduled departures”, Society \& Space, 29: 353-368.

VANNINI, Phillip, $201 \mathrm{lb}$, "Constellations of (in)convenience: disentangling the assemblages of Canada's west coast island mobilities", Social and Cultural Geography, 12 (5): 471 -492 .

VARGAS, José, 2007, "Liberalismo, neoliberalismo, postneoliberalismo", Revista MAD, 17: 66-89.

VELAZCO, Honorio, y Ángel DÍAZ DE LA RADA, 1997, La Lógica de la Investigación Etnográfica. Madrid, Editorial Trotta.

WATTS, Laura, y John URRY, 2008, "Moving methods, travelling times", Environment and Planning D: Society and Space, 26 (5): 860-874.

YÁÑEZ, Carlos, 2011 , "De remeros a pasajeros: memorias de viajes y cambios sociales en una isla", Revista de Historia Regional y Local, 3 (6): 23 1-252.

$\begin{array}{ll}\text { Receção da versão original / Original version } & 2017 / 04 / 14 \\ \text { Receção da versão revista / Revised version } & 2018 / 09 / 19 \\ \text { Aceitação / Accepted } & 2019 / 03 / 18 \\ \text { Pré-publicação online / Pre-published online } & 2019 / 12 / 31\end{array}$

